\title{
Classification of leprosy cases under field conditions in Bangladesh. II. Reliability of clinical criteria
}

\author{
G. GROENEN, * N. G. SAHA, $\dagger$ M. A. RASHID, \\ M. A. HAMID** \& S. R. PATTYN $\S$ \\ *Damien Foundation, Bangladesh, $†$ Danish-Bangladesh Leprosy \\ Mission, Nilphamari, Bangladesh, $\ddagger$ Jalchatra Hospital and Leprosy \\ Control Project, Damien Foundation, Bangladesh, **Jalchatra \\ Hospital and Leprosy Control Project, Damien Foundation, \\ Bangladesh and the §Institute of Tropical Medicine, Antwerpen, \\ Belgium
}

\section{Accepted for publication 25 November 1994}

Summary In 2 non-governmental organization projects 244 new leprosy patients in Bangladesh were classified in the field according to clinical criteria i.e. number of skin lesions and number of enlarged nerves.

Comparison of these classification results with the results of skin smears and biopsies yielded a sensitivity (for detection of a MB case) of $92 \cdot 1 \%$, but the 'unconfirmed MB rate' amounted to $52 \cdot 6 \%$.

In order to improve the reliability of the operational classification, several additional clinical criteria were investigated. It was found that neither the presence of anaesthesia in the skin lesions nor the presence of grade 2 disabilities or peripheral anaesthesia or voluntary muscle testing (VMT) impairment contributed to an improved classification. Counting the number of body areas showing signs of leprosy, which had proven very useful in other programmes, did not result in a more reliable classification in the 2 projects in Bangladesh.

The presence of clinical signs of lepromatous leprosy, more specifically nodules or diffuse infiltration, could be a useful addition to the classification criteria. If the sensitivity must remain higher than $90 \%$, the lowest 'unconfirmed MB rate' obtainable in Bangladesh, using clinical criteria only, is $46.4 \%$, for a sensitivity of $91.0 \%$. However, the inclusion of skin-smear results in the classification criteria could improve the sensitivity to $96.6 \%$ and lower the 'unconfirmed MB rate' to $40 \cdot 3 \%$. A reduction in MB overclassification will result in more efficient and more cost-effective leprosy control programmes.

\section{Introduction}

Many leprosy programmes rely on clinical criteria in order to classify the patients into paucibacillary (PB) and multibacillary (MB) groups. A first part of the present study ${ }^{1}$

ๆ Correspondence: ALERT, P.O. Box 165, Addis Ababa, Ethiopia. 
looked at the usefulness of skin-smear results in 2 programmes in Bangladesh: the Danish-Bangladesh Leprosy Mission Project in Nilphamari, and the Damien Foundation project in Jalchatra. The second part of the analysis looks into the following questions:

1 How reliable are the clinical criteria presently used?

2 Is it possible to identify additional criteria to make the clinical classification more accurate?

3 Is it possible to define a classification strategy which will keep MB overclassification to a minimum, without missing any $\mathrm{MB}$ case?

\section{Materials and methods}

These are described in detail in the first part of the study. ${ }^{1}$ A summary is given below.

From 1 March, to 31 July, 1993, all new cases (totalling 244) diagnosed in Nilphamari and Jalchatra leprosy control projects were enrolled in the study. The following data were recorded: skin lesions, skin infiltration, enlarged nerves, sensitivity of skin lesions (using a 0.5 gram nylon monofilament), deformities, results of sensory testing of hands (using a 1 gram nylon mono-filament) and feet (using a ballpoint pen), voluntary muscle testing of hands, feet and eyes, and WHO disability grading.

Skin smears were taken at 4 standard sites (which included 1 earlobe) and at the most active area of the most peripheral active lesion, excluding the face. The latter was also the site of a punch biopsy of 5-mm diameter. MDT treatment was prescribed in the field in function of the operational classification:

if $>=10$ lesions: $\mathrm{MB}$;

if $<=3$ lesions: $\mathrm{PB}$;

if 4 to 9 lesions:

if $>=2$ enlarged nerves: $\mathrm{MB}$;

if $<=1$ enlarged nerve: $\mathrm{PB}$;

whereby lesion $=$ either skin lesion or enlarged nerve.

The present study compares this operational classification with the 'bacteriological' classification based on biopsy and skin-smear results: a patient is bacteriologically classified as $\mathrm{MB}$ if the biopsy result is either $\mathrm{LL}$ or $\mathrm{BL}$ or $\mathrm{BB}$ or if the $\mathrm{BI}$ of the biopsy is positive or if the BI of the skin smear is positive at any single site. A patient is bacteriologically classified as PB if the biopsy result is either BT or TT or I and if the $\mathrm{BI}$ of the biopsy is negative and if the $\mathrm{BI}$ of the skin smears is negative.

\section{Results}

Out of the 244 patients diagnosed in Nilphamari (NIL) and Jalchatra (JAL), 173 (70.9\%) were classified in the field as $\mathrm{MB}$ and 71 as $\mathrm{PB}$, and 82 of the $\mathrm{MB}$ cases $(47 \cdot 4 \%)$ were bacteriologically confirmed while 7 of the PB cases $(9 \cdot 9 \%)$ were bacteriologically MB (see Table 1).

Clinical signs of lepromatous leprosy (diffuse infiltration, nodules, madarosis, nose 
Table 1. Operational and bacteriological classification of the leprosy patients

\begin{tabular}{|c|c|c|c|}
\hline \multirow[b]{2}{*}{ Bacteriological classification } & \multicolumn{2}{|c|}{$\begin{array}{l}\text { Operational } \\
\text { classification }\end{array}$} & \multirow[b]{2}{*}{ Total } \\
\hline & MB & PB & \\
\hline Bacteriologically confirmed $\mathrm{MB}^{1}$ & 82 & 7 & 89 \\
\hline $\begin{array}{l}\text { Confirmed PB cases without bacteriologically } \\
\text { confirmed MB evidence }\end{array}$ & 73 & 50 & 123 \\
\hline $\begin{array}{l}\text { Bacteriologically negative, no anatomopathological } \\
\text { signs of leprosy }\end{array}$ & 18 & 14 & 32 \\
\hline Total & 173 & 71 & 244 \\
\hline
\end{tabular}

\footnotetext{
${ }^{1}$ Biopsy result is LL or BL or BB, or BT or I with a positive $\mathrm{BI}$ in either the biopsy or the skin smear or both.

${ }^{2}$ Biopsy result is BT or TT or I, with a negative BI both in the biopsy and the skin smear.

${ }^{3}$ No evidence of leprosy found in the biopsy, and all skin smears negative. But clinical evidence of leprosy present in all patients (anaesthetic skin lesions with or without enlarged nerves: 24; enlarged nerves without anaesthetic skin lesions: 7; grade 2 disability of both feet: 1 ).

${ }^{4}$ If $>=10$ lesions: MB; if $<=3$ lesions: PB; if 4 to 9 lesions: MB if $>=2$ enlarged nerves; $\mathrm{PB}$ if $<=1$ enlarged nerve (whereby lesion = either skin lesion or enlarged nerve).
}

collapse and gynaecomastia) were found in 34 patients. Their characteristics are summarized in Table 2.

The overall number of skin lesions in each patient is given in Table 3. Because of the striking difference between the MB patients with lepromatous lesions and those without lepromatous lesions, these 2 groups are mentioned separately.

The number of body areas where a skin lesion is present were also counted, body areas being the head, the left arm, the right arm, the front of the trunk, the back of the trunk, the left leg and the right leg. It was observed that at least 3 body areas were involved in $100 \%$ of patients presenting 6 or more lesions, and in $72 \%$ of patients presenting 4 or 5 lesions.

Table 2. Presence of clinical signs of lepromatous leprosy in relation to bacteriological and operational classification of leprosy patients

Bacteriological classification

\begin{tabular}{|c|c|c|c|c|c|c|c|}
\hline \multirow{2}{*}{$\begin{array}{l}\text { Anatomo- } \\
\text { pathological } \\
\text { image }\end{array}$} & \multirow{2}{*}{$\begin{array}{c}\text { BI } \\
\text { (in biopsy or } \\
\text { skin smear) }\end{array}$} & \multirow[b]{2}{*}{$\begin{array}{l}\text { Operational } \\
\text { classification }^{2}\end{array}$} & \multicolumn{4}{|c|}{ Signs of lepromatous leprosy } & \\
\hline & & & $\begin{array}{c}\text { Diffuse } \\
\text { infiltration }\end{array}$ & Nodules & Madarosis & $\begin{array}{l}\text { Nose } \\
\text { collapse }\end{array}$ & Total \\
\hline LL & + & MB & 11 & $\left(6^{*}\right)$ & $(3 \dagger)$ & $(1 \dagger)$ & 11 \\
\hline $\mathrm{BL}$ & + & MB & 17 & $3\left(+6^{*}\right)$ & $(2 \dagger)$ & $(1 \dagger)$ & 20 \\
\hline BT & + & MB & 2 & & & & 2 \\
\hline Unknown $^{1}$ & + & MB & 1 & & & & 1 \\
\hline Total & & & 31 & $3\left(+12^{*}\right)$ & $(5 \dagger)$ & $(2 \dagger)$ & 34 \\
\hline
\end{tabular}

* Patients also presenting diff use infiltration; $\dagger$ patients also presenting either diff use infiltration or nodules.

${ }^{1} \mathrm{BI}$ in skin smear $=5+$.

${ }^{2}$ See Table 1 , note 4 . 
Table 3. Number of skin lesions in leprosy patients, in relation to bacteriological classification

\begin{tabular}{|c|c|c|c|c|c|c|c|c|c|c|}
\hline \multirow{2}{*}{$\begin{array}{l}\text { Bacteriological } \\
\text { classification }\end{array}$} & \multicolumn{10}{|c|}{ Number of skin lesions } \\
\hline & $0-3$ & $4-5$ & $6-9$ & $10-14$ & $15-19$ & $20-49$ & $50+$ & Mean & Median & Range \\
\hline $\begin{array}{l}\text { Bacteriologically } \\
\text { confirmed } \mathrm{MB}^{1} \\
\text { with lepromatous } \\
\text { lesions }\end{array}$ & 22 & 3 & 1 & 2 & 1 & 0 & 5 & 10 & 2 & $0-99+$ \\
\hline $\begin{array}{l}\text { Bacteriologically } \\
\text { confirmed MB } \\
\text { without leproma- } \\
\text { tous lesions }\end{array}$ & 7 & 3 & 6 & 5 & 5 & 20 & 9 & 30 & 22 & $1-99+$ \\
\hline $\begin{array}{l}\text { Confirmed PB cases } \\
\text { without bacterio- } \\
\text { logically confirmed } \\
\text { MB evidence }{ }^{2}\end{array}$ & 54 & 21 & 16 & 13 & 8 & 11 & 0 & 8 & 4 & $1-45$ \\
\hline $\begin{array}{l}\text { Bacteriologically } \\
\text { negative, no } \\
\text { anatomo- } \\
\text { pathological } \\
\text { signs of leprosy }\end{array}$ & 17 & 4 & 3 & 4 & 1 & 2 & 1 & 10 & 3 & $1-99+$ \\
\hline
\end{tabular}

\footnotetext{
${ }^{1}$ See table 1 , note 1 .

${ }^{2}$ See table 1 , note 2 .

${ }^{3}$ See table 1 , note 3 .
}

Anaesthesia of skin lesions was observed in 187 patients. The presence of anaesthesia in function of the bacteriological classification is given in Table 4.

Enlarged nerves were found in 219 patients. The number of enlarged nerves for each patient is given in Table 5 .

The number of extremities (the head being counted as an extremity) presenting enlarged nerves was counted for each patient. In $100 \%$ of patients presenting 5 or more enlarged nerves, at least 3 extremities were involved. In patients presenting 4 enlarged nerves, $65 \%$ showed an involvement of at least 3 extremities, and $35 \%$ of 2 extremities. In patients presenting 3 enlarged nerves, $50 \%$ showed an involvement of 3 extremities, $33 \%$ of 2 extremities and $17 \%$ of 1 extremity. Only $43 \%$ of patients presenting 2 enlarged nerves showed involvement of a single extremity.

Apart from the presence of enlarged nerves, nerve involvement due to leprosy may manif est itself peripherally through corneal anaesthesia, glove or stocking anaesthesia, impaired VMT results for the muscles of the face, the hands and the feet, and the presence of grade 2 disabilities. Grade 2 disability was present in 27 patients $(11 \cdot 1 \%)$. Peripheral anaesthesia or VMT impairment or both were found in all 27 patients with grade 2 disability and in an additional 105 patients. In 112 of the patients (45.9\%) there was neither peripheral anaesthesia, or VMT impairment, or grade 2 disability. Of these, $19 \%$ were confirmed MB.

Among the patients with single limb involvement, the confirmed $\mathrm{MB}$ amounted to $23 \%$, and to $66 \%$ among patients with involvement of 2 or more limbs.

The number of body areas showing signs of leprosy, either skin lesions or enlarged nerves or nerve function impairment, is given in Table 6. 
Table 6. Number of body areas (head, left arm, right arm, front of trunk, back of trunk, left leg, right leg) presenting signs of leprosy: either skin lesions and/or enlarged nerves and/or nerve function impairment (anaesthesia, VMT impairment, grade 2 disability), in leprosy patients in relation to bacteriological classification

\begin{tabular}{|c|c|c|c|c|}
\hline \multirow[b]{2}{*}{ Bacteriological classification } & \multicolumn{4}{|c|}{ Number of body areas involved } \\
\hline & 1 & 2 & 3 & $4+$ \\
\hline Bacteriologically confirmed $\mathrm{MB}^{1}$ & 9 & 6 & 13 & 61 \\
\hline $\begin{array}{l}\text { Confirmed leprosy without } \\
\text { bacteriologically confirmed MB } \\
\text { evidence }\end{array}$ & 41 & 19 & 15 & 48 \\
\hline $\begin{array}{l}\text { Bacteriologically negative, no } \\
\text { anatomopathological signs of leprosy }\end{array}$ & 10 & 8 & 14 & 0 \\
\hline
\end{tabular}

\footnotetext{
${ }^{1}$ See Table 1 , note 1 .

${ }^{2}$ See Table 1 , note 2 .

${ }^{3}$ See Table 1 , note 3 .
}

number of cases classified as MB without bacteriological evidence (the 'false positives' among those classified as $\mathrm{MB}$ ). The percentage of cases classified as $\mathrm{MB}$ without bacteriological evidence among all cases classified as $\mathrm{MB}$, can be called the 'unconfirmed MB rate', and corresponds to: 1 - predictive value $\mathrm{MB}$.

Bef ore analysing the findings of the present study, the question should be asked: are all patients included in the study truly leprosy cases? In 32 patients, the biopsy and the skin smears were negative. However, 24 of these (see Table 4) presented with anaesthetic skin lesions (a cardinal sign of leprosy) with or without enlarged nerves, while 7 of the remaining 8 presented suspect but sensitive skin lesions with enlarged nerves (also a cardinal sign of leprosy), and the 1 remaining patient presented grade 2 disabilities on both feet. Most leprologists would agree that the presence of anaesthetic skin lesions and the presence of enlarged nerves are clear clinical signs of leprosy in a leprosy endemic area, even if the biopsy shows no evidence of leprosy. Thus the diagnosis of leprosy could be justified in at least 31 of these 32 patients. Nevertheless, the presence of anaesthesia should be considered a doubtful criterion at best, in view of the fact that Table 4 shows that $77 \%$ of all patients present anaesthetic lesions, including $23 \%$ of LL patients and $40 \%$ of BL patients. The interpretation of sensory testing, however well done, is influenced by too many factors to remain strictly objective. In this particular group of patients, it seems as if the expectations of the examiners have biased the sensory testing results. The interpretation of nerve enlargement is equally subject to inter- and intraobserver variation. The presence of grade 2 disability without any other sign of leprosy in a patient could suggest several other diagnoses (for instance ideopathic peripheral neuropathy).

Thus, we cannot say with certainty that all 244 cases are truly leprosy patients. However, since it is equally impossible to say with certainty that they do not have leprosy, all patients will be included in the analysis.

Of the 244 patients in the study, 89 are bacteriologically classified as MB, and 155 as non-MB (see Table 1). The application of the criteria of the operational classification resulted in correctly identifying 82 of $89 \mathrm{MB}$ cases, a 'sensitivity' of $92 \cdot 1 \%$. For 91 of 173 
patients there was no bacteriological evidence of MB leprosy, an 'unconfirmed MB rate' of $52 \cdot 6 \%$.

Analysis of the individual patient records reveals that the classification criteria were not always applied rigorously, e.g. a patient with only 2 lesions classified as $\mathrm{MB}$, or a patient with 2 enlarged nerves classified as PB. But this does not significantly alter the results: strict application of the criteria would still correctly classify $82 \mathrm{MB}$ cases ('sensitivity': 92.1\%) while 101 patients would be classified as MB without bacteriological evidence ('unconfirmed MB rate': $55 \cdot 2 \%$ ).

The goal of the operational classification is to miss as few MB cases as possible. Short of treating all patients as $\mathrm{MB}$, the highest 'sensitivity' obtainable, using the number of skin lesions and the number of enlarged nerves as classification criteria, would be $96.6 \%$, if all patients presenting 6 or more skin lesions or 2 or more enlarged nerves would be treated as MB. But 3 out of $89 \mathrm{MB}$ cases would still be missed, and there would be 105 'false positives' - an 'unconfirmed MB rate' of $55 \cdot 0 \%$.

Since the 'unconfirmed MB rate' is very high, investigations should determine if any additional clinical criteria could be helpful in increasing the reliability of the operational classification. A study in Ethiopia ${ }^{5}$ shows that a combination of 5 or 6 clinical criteria produces the most reliable results. It is unforturate that the Ethiopian study does not start its analysis with the criteria 'number of skin lesions' and 'number of enlarged nerves', which would have made comparison with the present study easier. In addition, no systematic biopsy taking was done in Ethiopia: as a result, the reference $\mathrm{MB}$ classification had to be based on a combination of skin-smear results and clinical criteria. But it is exactly these clinical criteria which are under investigation. Thus the sensitivity, specificity and predictive values of that study cannot be compared to the present study. A score chart used in Papua New Guinea ${ }^{6}$ rates 8 clinical criteria from 1 to 3 , a total score of $>=12$ resulting in an $\mathrm{MB}$ classification. The reliability of this approach is not analysed.

A study in $\mathrm{Nepal}^{7}$ discussed the reliability of a system based on affected body areas, while at the same time using a computer simulation to study various other methods of $\mathrm{PB} / \mathrm{MB}$ classification.

In the present study, various additional clinical criteria were added to the baseline criteria (number of skin lesions and number of enlarged nerves) in order to examine whether a more reliable classification could be obtained. As already pointed out, anaesthesia of skin lesions (see Table 4) was present in 187 patients spread out across the whole spectrum of the bacteriological classification. Although anaesthesia was observed in almost all PB patients, it was also present in $49 \%$ of the MB patients, including $23 \%$ of the LL patients. The suspected examiner bias has already been discussed above. In this particular study, the presence of anaesthesia does not contribute to a more correct classification of the patients.

The number of body areas involved is not helpful either. Most patients have at least 3 areas involved the moment they present 4 or more skin lesions, and when 2 or more nerves are enlarged, this usually involves at least 2 limbs, while almost $50 \%$ of the patients (including $19 \%$ of the MB patients) do not present any peripheral neurological impairment.

If all the patients who were presenting at least 2 body areas with leprosy signs (see Table 6) were considered MB, this would result in a 'sensitivity' of $89.9 \%$ and an 'unconfirmed $\mathrm{MB}$ rate' of $56.5 \%$. If the presence of at least 2 enlarged nerves were 
included as an MB criterion, the 'sensitivity' would increase to $93.3 \%$, but the 'unconfirmed MB rate' would be even higher, at $57 \cdot 8 \%$.

If the M B criterion were presence of 3 body areas affected by leprosy, the 'sensitivity' would be $83 \cdot 1 \%$, and the 'unconfirmed MB rate' would be $51 \cdot 0 \%$. This is in marked contrast with the study in Nepal, ${ }^{7}$ where the criterion of 3 affected body areas (in patients who had a biopsy) resulted in a 'sensitivity' of $93 \%$ and an 'unconfirmed MB rate' of $33 \%$. If the criterion of 2 affected body areas were used, the 'sensitivity' was pushed up to $100 \%$, while the 'unconfirmed MB rate' was $36 \%$. The reason for this marked difference is to be found in the higher number of $\mathrm{MB}$ patients in Bangladesh with only 1 or 2 affected body areas. In Bangladesh, 9 of $89 \mathrm{MB}$ patients $(10 \%)$ show involvement of a single body area, and 15 of $89(16.9 \%)$ of 1 or 2 areas. In Nepal, these figures are 0 of 31 , and 2 of $31(6 \cdot 5 \%)$, respectively.

Most likely, this is due to earlier case detection in Bangladesh, as illustrated by the proportion of WHO grade 2 disabilities among newly-detected cases: $11 \cdot 1 \%$ in Bangladesh against $22 \%$ in Nepal. This would suggest that the body area criterion would be more useful in advanced cases.

The presence of clinical signs of lepromatous leprosy is a very sensitive and specific indicator of MB leprosy (see Table 2). All 34 patients with lepromatous signs are MB cases. The presence of diffuse infiltration in 2 histological BT patients, although they presented a positive BI, may be doubted. This could be a manifestation of examiner bias. However, all observations made by the field worker were checked by the medical officer. Although the presence of concomitant diseases presenting with similar clinical signs was not explicitly excluded, no evidence of any such disease was found in the biopsies, and all patients presenting clinical signs of lepromatous leprosy had a positive BI. Thus, the attribution of these signs to leprosy seems justified.

The presence in a BL patient of madarosis ( 2 patients) or nose collapse ( 1 patient) would suggest we are dealing with LL patients rather than BL patients.

Since no patient presented with gynaecomastia, and the 2 patients with nose collapse and the 5 patients with madarosis also presented diffuse infiltration or nodules or both, the presence of diffuse infiltration or nodules should be a useful addition to the clinical criteria of the operational classification. The addition of the criterion of lepromatous signs to those outlined under materials and methods would increase the 'sensitivity' to $94.4 \%$, but the 'unconfirmed MB rate' would still be $54.8 \%$. If the MB criteria were the presence of either lepromatous signs, or of 10 or more skin lesions, or of 3 or more enlarged nerves, the 'sensitivity' would be $93 \cdot 3 \%$, and the 'unconfirmed MB rate' $49 \cdot 4 \%$. If the last criterion was made more restricted (presence of 3 or more enlarged nerves, if also 3-9 skin lesions are present) the 'sensitivity' would be $91.0 \%$ and the 'unconfirmed MB rate' $46 \cdot 4 \%$.

A lower 'unconfirmed MB rate' could not be obtained without lowering the 'sensitivity' below $90 \%$.

This discussion suggests that an operational classification based on clinical criteria will inevitably result in a very high overclassification of MB cases.

The first part of this study ${ }^{1}$ shows that reliable skin-smear examinations may contribute to the reliability of the classification. Based on skin-smear results alone, $88.8 \%$ of the MB cases are correctly identified without overclassifying a single case. Of those $\mathrm{MB}$ cases missed, $60 \%$ had a $\mathrm{BI}$ of $1+$ in the dermal nerves only. If these cases were to be considered PB, the 'sensitivity' of the skin-smear criterion would be $94 \cdot 7 \%$. 
Table 7. Sensitivity (defined as: proportion of patients presenting either a biopsy result of LL or BL or BB or a positive BI in either the biopsy or the skin smear, correctly identified as $\mathrm{MB}$ ) and false $\mathrm{MB}$ rate (defined as: proportion of patients without histological MB evidence and with negative skin smears, identified as MB) for various sets of classification criteria

\begin{tabular}{|c|c|c|}
\hline Classification criteria for $\mathrm{MB}$ & $\begin{array}{c}\text { Sensitivity } \\
(\%)\end{array}$ & $\begin{array}{c}\text { False } M B \text { rate } \\
(\%)\end{array}$ \\
\hline $\begin{array}{l}\text { Either }>=10 \text { lesions (skin or nerve) } \\
\text { or } 4-9 \text { lesions (skin or nerve) } \\
\text { with }>=2 \text { enlarged nerves }\end{array}$ & $92 \cdot 1$ & $52 \cdot 6$ \\
\hline $\begin{array}{l}\text { Either }>=6 \text { skin lesions } \\
\text { or }>=2 \text { enlarged nerves }\end{array}$ & $96 \cdot 6$ & $55 \cdot 0$ \\
\hline $\begin{array}{l}\text { Either presence of lepromatous signs } \\
\text { or }>=10 \text { skin lesions } \\
\text { or }>=3 \text { enlarged nerves }\end{array}$ & $93 \cdot 3$ & $49 \cdot 4$ \\
\hline $\begin{array}{l}\text { Either presence of lepromatous signs } \\
\text { or }>=10 \text { skin lesions } \\
\text { or } 3-9 \text { skin lesions } \\
\text { plus }>=3 \text { enlarged nerves }\end{array}$ & $91 \cdot 0$ & $46 \cdot 4$ \\
\hline$>=2$ body areas affected & $89 \cdot 9$ & $56 \cdot 5$ \\
\hline $\begin{array}{l}\text { Either }>=2 \text { body areas affected } \\
\text { or }>=2 \text { enlarged nerves }\end{array}$ & $93 \cdot 3$ & $57 \cdot 8$ \\
\hline Skin smear positive & $88 \cdot 8$ & 0 \\
\hline $\begin{array}{l}\text { Either skin smear positive } \\
\text { or }>=20 \text { skin lesions } \\
\text { or }>=4 \text { enlarged nerves }\end{array}$ & $96 \cdot 6$ & $40 \cdot 3$ \\
\hline
\end{tabular}

If various combinations of skin-smear examinations and clinical criteria with different cut-off points are looked into, the most reliable result would be the following: if the criteria for MB classification are either a positive skin smear, or 20 or more skin lesions, or 4 or more enlarged nerves, the 'sensitivity' is $96 \cdot 6 \%$, while the 'unconfirmed $\mathrm{MB}$ rate' is $40 \cdot 3 \%$.

These figures are valid if skin smears are taken at the 4 standard sites (see Materials and Methods) and at the most active peripheral site. If skin smears are taken only at the earlobe and the most active peripheral site, the 'sensitivity' becomes $95 \cdot 5 \%$ and the 'unconfirmed MB rate' 40.6\%.

For easy reference, Table 7 summarizes the 'sensitivities' and 'false MB rates' obtained by using the most representative of the various sets of criteria discussed in this article.

\section{Conclusion}

Each patient classified as $\mathrm{MB}$ without proper justification will require a treatment regimen which is 14 times more expensive than the PB regimen, while he will at the same time require 4 times as many monthly medical contacts. Thus $\mathrm{MB}$ overclassification will have considerable consequences in terms of drug budget and workload of the field workers.

To illustrate this with an example: a programme has to treat 1000 patients, 400 of whom are bacteriologically confirmed MB cases. The choice is between strategy $Y$ with a 
'sensitivity' of $95 \%$ (380 MB cases found) and a 'unconfirmed MB rate' of $52 \%$, and strategy $\mathrm{Z}$ with a 'sensitivity' of $90 \%$ (360 MB cases found) and an 'unconfirmed $\mathrm{MB}$ rate' of $41 \%$. Strategy Y will be almost US\$7300 more expensive for the drug cost alone, while it will also require 3276 monthly medical contacts in excess of strategy $\mathrm{Z}$. The programme planner has to decide whether this extra cost is justified by 20 additional $\mathrm{MB}$ cases which would be found by strategy Y.

The present analysis suggests that the inclusion of the skin-smear results would considerably improve the reliability of the classification strategy. In many programmes, skin smears are taken, but their results are not used optimally, if used at all, often because the validity of these results is doubted. Such programmes would profit tremendously from an upgrading of the quality of their laboratory facilities. Ref resher courses for the laboratory technician and regular quality control of smear taking and smear reading would result, for a limited cost, in improved reliability of the smear results. This would permit the inclusion of these smear results in the classification criteria, which would lead to more $\mathrm{MB}$ cases being correctly classified and less unconfirmed $\mathrm{MB}$ cases being treated as $\mathrm{MB}$, thus resulting in a more cost-effective programme. However, in programmes without laboratory facilities, the introduction of skin-smear examination may not be cost-effective in view of the cost of hiring and training qualified personnel, of installing the laboratory and of setting up a system to assure the continued quality of its performance.

\section{References}

1 Groenen G, Saha NG, Rashid MA, Hamid MA, Pattyn SR. Classification of leprosy cases under field conditions in Bangladesh. I. Usef ulness of skin-smear examinations. Lepr Rev, 66: 126-33.

2 Georgiev GD, McDougall AC. Skin smears and the Bacteriological Index (BI) in multiple drug therapy control programmes: An unsatisfactory and potentially hazardous state of affairs. Int J Lepr, 1988; 56: 101-4.

3 Georgiev GD, McDougall AC. A re-appraisal of clinical and bacteriological criteria in the implementation of multiple drug therapy for leprosy control programmes and proposals for their better use. Lepr Rev, 1990; 64: 64-72.

4 McDougall AC. Editorial. Leprosy control and the implementation of multiple drug therapy: to what extent can the operational strategy be simplified for primary health care? Lepr Rev, 1992; 63: 193-98.

5 Becx-Bleumink M. Allocation of patients to paucibacillary or multibacillary drug regimens for the treatment of leprosy - a comparison of methods based mainly on skin smears as apposed to clinical methodsalternative clinical methods for classification of patients. Int J Lepr, 1991, 59: 292-303.

6 Nash JE, Hudson BJ, Pyakalyia T. Leprosy score chart to assist classification. Lepr Rev, 1989; 60: $242-3$.

7 Van Brakel WH, De Soldenhoff R, McDougall AC. The allocation of leprosy patients into paucibacillary and multibacillary group for multidrug therapy, taking into account the number of body areas affected by skin, or skin and nerve lesions. Lepr Rev, 1992; 63: 231-45. 